\title{
Marlène SCHIAPPA, Jérémie PELTIER, Laïcité, point !
}

La Tour d'Aigues, Éditions de l'Aube, 2017

\section{Philippe Ségur}

\section{(2) OpenEdition}

\section{Journals}

Édition électronique

URL : http://journals.openedition.org/rdr/344

DOI : $10.4000 /$ rdr.344

ISSN : 2534-7462

\section{Éditeur}

Presses universitaires de Strasbourg

\section{Édition imprimée}

Date de publication : 6 novembre 2018

Pagination : 175-176

ISBN : 979-10-344-0023-2

ISSN : 2493-8637

\section{Référence électronique}

Philippe Ségur, « Marlène SCHIAPPA, Jérémie PELTIER, Laïcité, point! 》, Revue du droit des religions [En ligne], 6 | 2018, mis en ligne le 25 novembre 2019, consulté le 19 novembre 2020. URL : http:// journals.openedition.org/rdr/344 ; DOI : https://doi.org/10.4000/rdr.344

Ce document a été généré automatiquement le 19 novembre 2020.

\section{(c) (7) (5)}

La revue du droit des religions est mise à disposition selon les termes de la Creative Commons Attribution - Pas d'Utilisation Commerciale 4.0 International - CC BY-NC 4.0. 


\section{Marlène SCHIAPPA, Jérémie PELTIER, Laïcité, point!}

La Tour d'Aigues, Éditions de l'Aube, 2017

Philippe Ségur

\section{RÉFÉRENCE}

Marlène SCHIAPPA, Jérémie PELTIER, Laïcité, point !, La Tour d'Aigues, Éditions de l'Aube, 2017, 71 p.

Comme le titre le laisse entendre, il s'agit d'un ouvrage militant. Le lecteur est invité à le prendre pour tel et à n'y pas chercher nouveauté argumentative ni objectivité d'un travail de recherche. On y trouvera, en revanche, une pédagogie grand public de la lutte féministe et anti-communautariste, de la défense de la liberté d'expression et de la neutralité des services publics, en particulier de celui de l'enseignement, au risque parfois d'escamoter certaines données pour les besoins du plaidoyer. Les auteurs rappellent ainsi que, d'après la loi de 1905, la République ne salarie ni ne subventionne aucun culte, mais omettent de dire que le texte prévoit l'existence d'aumôneries et l'inscription aux budgets de l'État et des collectivités locales des crédits nécessaires pour "assurer le libre exercice des cultes dans les établissements publics tels que lycées, collèges, écoles, hospices, asiles et prisons " (art. 2). De même, est-il permis de voir dans l'affirmation selon laquelle "la laïcité est la condition sine qua non de l'émancipation du genre humain» (p.15) un raccourci péremptoire qui est loin de régler la question. Il n'est que de se souvenir, avec le Marx de La Question juive, que l'État peut être un État laïque sans que l'homme soit libre, ou que, à rebours des proclamations dogmatiques, le criterium d'évaluation du Bonheur National Brut est issu d'un État religieux. En définitive, si l'on souscrit à la plupart des idées libérales de ce petit livre et si l'on peut le juger utile à leur diffusion, il n'est pas certain que sa démarche délibérément simplificatrice donne à la notion complexe de laïcité une plus grande clarté. Combien de fois le mot « laïcité » est-il inscrit dans la loi de séparation 
des Églises et de l'État? demande la secrétaire d'État chargée de l'Égalité entre les femmes et les hommes et de la Lutte contre l'homophobie. Tout est là, car la réponse est emblématique des difficultés qui ont suivi : la loi de 1905 n'en parle pas.

\section{AUTEURS}

\section{PHILIPPE SÉGUR}

Professeur de droit public, Université de Perpignan Via Domitia, Centre du droit économique et du développement (CDED) 